\title{
LA MORALIDAD DE LOS AZTECAS, ENTRE LA RECONSTRUCCIÓN HISTÓRICA Y LA RECONSTRUCCIÓN RACIONAL
}

The Morality of the Aztecs, between Historical Reconstruction and Rational

Reconstruction

José María Filgueiras Nodar, Universidad del Mar, México

Correo electrónico: jofilg@huatulco.umar.mx

Recepción: 7/08/2019

Aceptación: 17/12/2019

Resumen. Este ensayo proporciona un panorama de la moralidad de los aztecas, exponiendo en primer lugar su concepción de la persona y el modo en que tratan el tema de la libertad personal. Posteriormente, expone las virtudes de algunos ideales de persona, así como el proceso educativo capaz de aportar las virtudes que definen dichos ideales. El texto finaliza exponiendo brevemente un principio jurídico de nivel muy general: in quálli, in yéctli. A lo largo del artículo se intenta establecer puntos de contacto con algunos debates éticos contemporáneos.

Palabras clave: ética, aztecas, filosofía náhuatl, Miguel León-Portilla, filosofía latinoamericana.

Abstract. This essay provides an overview of Aztec morality, showing at first their conception of person and the way they dealt with personal freedom. Subsequently, it expounds the virtues of several ideal models a person could be, and the educational process capable of bringing the virtues that define those models. The text ends with a brief exposition of a legal principle in a very general level: in quálli, in yéctli. Along the article, we attempt to establish points of contact with some contemporary debates in the field of ethics.

Keywords: ethics, Aztecs, Nahuatl philosophy, Miguel León-Portilla, Latin American philosophy. 


\section{enn-claves}

\section{Introducción}

A pesar del destructivo impacto de la Conquista, es bastante lo que se conoce de la cultura mexica, ${ }^{1}$ incluido lo que León-Portilla denomina su filosofía. Este artículo seleccionará, de entre la misma, todos aquellos aspectos relacionados con la moralidad, ${ }^{2}$ buscando trazar un panorama relativamente completo de ésta. Para exponer la motivación del presente texto, debe hacerse referencia a Kwame A. Appiah y su apuesta por una ética experimental. ${ }^{3} \mathrm{Al}$ igual que Appiah, se considera que la ética debe apegarse más a los datos empíricos. Aunque en su libro este autor se refiere sobre todo a las neurociencias y la economía, se cree que tal animus empirista debería extenderse también a ciencias sociales como la antropología o la historia, precisamente el objeto de este texto, que presentará una concreción histórica de la moralidad.

Para ahondar en tales intenciones, resulta útil la conocida categorización de géneros establecida por Richard Rorty para la historiografía filosófica. ${ }^{4}$ Usando su terminología, se señalará que las reconstrucciones históricas, es decir, las descripciones de los pensadores del pasado en sus propios términos, o en términos comprensibles para un auditorio de su época, parecen ser tarea de los historiadores de las ideas. Por otro lado, las reconstrucciones racionales, que tratan a los pensadores del pasado como contemporáneos, imponiéndoles el vocabulario de hoy o moviéndolos a tomar partido en los debates actuales, se prestarían más al trabajo puramente filosófico. Este texto se moverá entre ambos polos: de las reconstrucciones históricas tomará su intención de apegarse con

\footnotetext{
${ }^{1}$ Si bien se reconoce que es una cuestión en la que debería profundizarse, a lo largo del texto se usarán las expresiones 'nahuas', 'mexicas' y 'aztecas' de forma indistinta.

${ }^{2}$ Se hace referencia aquí a la conocida distinción entre ética y moral, señalada por pensadores de las más variadas tradiciones, según la cual ambas expresiones guardan entre sí la misma relación que, por ejemplo, 'sociología' y 'sociedad' o 'biología' y 'vida'. La moralidad sería entonces un conjunto de prácticas y normas que regulan el comportamiento de individuos y comunidades, mientras que la ética vendría a ser un ejercicio de reflexión - que se podría caracterizar, sin ánimo de entrar en debates, como racional o crítica - ejercido sobre la moral. Véase Adela Cortina y Emilio Martínez Navarro, Ética (Madrid: Akal, 2008), 9-22; también la exposición histórica de Ana Marta González, "Ética y moral. Origen de una diferencia conceptual y su trascendencia en el debate ético contemporáneo", Anuario Filosófico, núm. 33 (2000): 797-832.

3 Kwame Anthony Appiah, Experiments in Ethics (Cambridge, MA: Harvard University Press, 2008).

${ }^{4}$ Richard Rorty, "La historiografía de la filosofía: cuatro géneros", en Richard Rorty, Jerome B. Schneewind y Quentin Skinner (eds.), La filosofía en la historia. Ensayos de historiografía de la filosofía (Barcelona: Paidós, 1990), 69-98.
} 


\section{enn-claves}

fidelidad a la época y cosmovisión elegida; de las reconstrucciones racionales destacará sus posibilidades para el diálogo, tratando de relacionar ciertas concepciones de la cosmovisión elegida con otros conceptos y preocupaciones de la ética.

Un elemento clave para las reconstrucciones históricas tiene que ver con la fidelidad de las fuentes elegidas. En La filosofía náhuatl estudiada en sus fuentes, León-Portilla menciona una serie de lugares donde se pueden encontrar las ideas principales de la ética náhuatl, como el Huehuetlatolli o la Historia general de las cosas de Nueva España, de Fray Bernardino de Sahagún, quien se embarcó en una completa investigación que le ha llevado a merecer calificativos como "pionero de la antropología"5 o "primer antropólogo en Nueva España". ${ }^{6}$

¿Fue Sahagún capaz de traducir de manera fiel todo el conocimiento acumulado a lo largo de su investigación? Aun suponiendo que ésta no tuviese fisuras, lo cual es siempre arriesgado, trasladar de modo fiel tales contenidos a un lenguaje y un universo cultural extraño es tarea extremadamente difícil. Por otra parte, ya que la intención de Sahagún era la conversión, surge el riesgo añadido de una cristianización de la moral náhuatl. Estos dos problemas podrían en principio comprometer la faceta de reconstrucción histórica que posee esta exposición.

No se cree que esto sea necesariamente un problema para alcanzar los objetivos que se persiguen en el texto: si bien para la historiografía tal vez sea necesario comprobar que lo dicho por los historiadores se corresponde (como diría Leopold von Ranke) con lo que ocurrió en realidad, la filosofía puede renunciar a ese prurito de objetividad con miras a otros intereses. El carácter híbrido de este texto, entre la reconstrucción histórica y la reconstrucción racional, parecería servir para salvar este escollo.

Debe decirse también que la fidelidad de la propuesta de Sahagún parece ser más que suficiente para muchos especialistas, como Miguel León-Portilla. De este modo, parece que apegarse a Sahagún es una buena manera de hacer que la presente lectura contenga ese componente de reconstrucción histórica que le aporta especial interés. Después de haber

5 Miguel León-Portilla, Bernardino de Sahagún. Pionero de la antropología (México: Universidad Nacional Autónoma de México-Instituto de Investigaciones Históricas, 1999).

${ }^{6}$ Florencio Vicente Castro y José Luis Rodríguez Molinero, Bernardino de Sahagún. El primer antropólogo en Nueva España (Siglo XVI) (Salamanca: Universidad de Salamanca, 1986). 


\section{enn-claves}

apartado del camino, de forma apresurada, el problema hermenéutico, se puede comenzar a exponer la moralidad mexica.

\section{La concepción mexica de la persona}

El punto de partida para ello será lo que podría denominarse su antropología filosófica, comenzando por la cuestión del origen de los seres humanos, que debe entenderse en "un doble plano, mítico-religioso por una parte y filosófico por otra". 7 El primer plano, que considera la creación de los humanos como un resultado directo de la intervención divina, aparece expresado en mitos como la creación de Cipáctonal y Uxumuco, primera mujer y primer hombre, a cargo de los cuatro primeros dioses, los hijos de Ometecuhtli, el Señor de la Dualidad (mito ilustrado en el Códice Vaticano A 3738). También en el mito, recogido por Fray Gerónimo de Mendieta en su Historia Eclesiástica Indiana o con ligeras variantes por Ángel María Garibay en la Épica náhuatl, de que los primeros seres humanos brotaron de la tierra después de que el sol lanzara una flecha contra ella. Estos primeros humanos habrían nacido incompletos, pero de algún modo consiguieron unirse para engendrar un hijo, del cual descendería toda la especie humana.

León-Portilla señala otros textos en los cuales el mito experimenta un proceso de racionalización (semejante, podría decirse, a la que se produjo en la Antigua Grecia en los momentos del origen de la filosofía). ${ }^{8}$ Se trata de la narración del viaje de Quetzalcóatl al Mictlan, una conocida historia relacionada con la Leyenda de los Soles. En su comentario a dicho texto, León-Portilla señala diversos aspectos interesantes, uno de los cuales atañe especialmente a esta exposición: la idea de que el humano es un ser necesario para los dioses. Éstos, dicen los códices, han creado al hombre con una clara intención, como vemos en el siguiente fragmento:

\footnotetext{
${ }^{7}$ Miguel León-Portilla, La filosofía náhuatl estudiada en sus fuentes (México: Universidad Nacional Autónoma de México, 1974), 181.

8 "Debemos considerar la historia de la filosofía griega como el proceso de progresiva racionalización de la concepción religiosa del mundo implícita en los mitos". Werner W. Jaeger, Paideia. Los ideales de la cultura griega (México: Fondo de Cultura Económica, 1944), 173.
} 
Y luego fue Quetzalcóatl al Mictlan: se acercó a Mictlantecutli y a Mictlancíhuatl y en seguida les dijo:

Vengo en busca de los huesos preciosos que tú guardas, vengo a tomarlos.

Y le dijo Mictlantecutli: ¿Qué harás con ellos Quetzalcóatl?

Y una vez más dijo [Quetzalcóatl]: los dioses se preocupan porque alguien viva en la tierra. ${ }^{9}$

La narración prosigue contando las pruebas que Mictlantecuthli pone a Quetzalcóatl hasta que éste consigue los huesos de los hombres que se habían creado en los soles anteriores, con malos resultados, para realizar un nuevo intento, el cual por fin tiene éxito. Pero lo que resulta más interesante para este recuento de las concepciones aztecas sobre la persona es la frase que cierra el texto: los dioses se preocupan, "se afligen [...] porque alguien viva en la tierra. Algo así como si fuera misteriosamente necesaria a la divinidad la existencia del hombre". ${ }^{10}$ Una primera lectura de esta necesidad es proporcionada por la mística guerrera de Huitzilopochtli, según la cual éste, el Sol, necesita de la sangre humana para seguir alumbrando. Mercedes de la Garza expresa esta idea diciendo que el ser humano (en concreto, su sangre, su preciosa eztli) sustenta a los dioses, y éstos sustentan al mundo, produciendo lo que ella denomina una "explicación antropocéntrica del cosmos". ${ }^{11}$ Se considera que tal explicación podría abrir interesantes reflexiones para los estudiosos de la ética ambiental comparada. ${ }^{12}$

Pero la lectura en clave de mística guerrera, dice León-Portilla, no agota la significación de esta necesidad que los dioses sienten por el género humano. Hay una segunda lectura, que para este autor pertenece a "lo más elevado del pensamiento náhuatl", ${ }^{13}$ según la cual la creación de los seres humanos y, en general, de la totalidad de las cosas, es decir, la difusión de Ometéotl hacia fuera de sí mismo, no tiene otro motivo que el deseo divino de divertirse contemplando el espectáculo proporcionado por los transitorios habitantes de tlaltípac (la superficie terrestre). Así, puede apreciarse, por ejemplo, en el siguiente fragmento del Códice Florentino, en el que aparece un tema común

\footnotetext{
${ }^{9}$ León-Portilla, La filosofía náhuatl, 183.

${ }^{10}$ Ibid., 184.

${ }^{11}$ Mercedes de la Garza, El hombre en el pensamiento religioso náhuatl y maya (México: Universidad Nacional Autónoma de México, 1978), 20.

${ }^{12}$ J. Baird Callicott, Earth's Insights. A Survey of Ecological Ethics from the Mediterranean Basin to the Australian Outback (Berkeley: University of California Press, 1994).

${ }^{13}$ León-Portilla, La filosofía náhuatl, 200.
} 


\section{enn-claves}

a numerosos análisis filosóficos, como es el rol de la actividad humana, aparentemente libre, cuando es vista por los ojos de Dios o, como diría Baruch Spinoza, sub specie aeternitatis. Para los aztecas, se trata de la acción de los seres humanos observada desde el punto de vista de Tloque Nahuaque, la principal deidad:

En el centro de la palma de su mano nos tiene colocados, nos está moviendo a su antojo.

Nos estamos moviendo, como canicas estamos dando vueltas, sin rumbo nos remece.

Le somos objetos de diversión: de nosotros se ríe. ${ }^{14}$

Entonces, sea para que el constante suministro de sangre mantenga girando al Sol, sea porque la divinidad desea divertirse observando las acciones de su creación, los humanos aparecen como necesarios para el mantenimiento del orden cósmico, lo cual explica la preocupación de los dioses por la creación de la humanidad. Dicho esto, se puede pasar ahora a otro aspecto relacionado: ¿cuál es la constitución esencial del ser humano según el pensamiento náhuatl? Como sucede con tantos otros aspectos de su cultura, los nahuas responden a esta pregunta usando un difrasismo, recurso que expresa "una misma idea por medio de dos vocablos que se completan en el sentido, ya por ser sinónimos, ya por ser adyacentes". ${ }^{15}$ En este caso, los dos vocablos son 'rostro' y 'corazón': in ixtli, in yóllotl. La cara y el corazón sirven a los nahuas para representar el dinamismo intrínseco del ser humano, así como la constitución básica de su estructura moral. León-Portilla subraya la coincidencia con el pensamiento griego, que identificaba el rostro con la personalidad. Por su parte, la referencia al corazón se debe a que este órgano era para los nahuas el asiento de la voluntad y la valentía, además de que jugaba un papel importante en el mantenimiento del orden cósmico, al ser necesario, como se ha visto, para alimentar a los dioses. Un fragmento del Códice Matritense expresa de un modo muy claro esta doctrina de la persona, ubicándola además como ideal supremo de la educación:

\footnotetext{
${ }^{14}$ Ibid., 199.

15 Ángel María Garibay, Llave del Náhuatl. Colecciones de trozos clásicos, con gramática y vocabulario náhuatl-castellano, para utilidad de los principiantes (México: Porrúa, 2007), 115.
} 


\section{enn-claves}

El hombre maduro:

corazón firme como la piedra, corazón resistente como el tronco de un árbol;

rostro sabio, dueño de un rostro y de un corazón, hábil y comprensivo. ${ }^{16}$

Estas características del hombre maduro [omácic oquichtli] aparecen adaptadas a los requerimientos de muy diversas profesiones, desde los amantéctal o artistas de los trabajos de plumería hasta los pochtecas, comerciantes que recorrían los caminos del imperio. Aparecen también mencionadas para los gobernantes, transformándose en un verdadero catálogo de virtudes, que se verá pronto. Antes, debe repararse en un tema de particular relevancia para la ética, el problema de la libertad personal, que aparece, como es sabido, en diversas tradiciones. ${ }^{17}$ León-Portilla afirma que este problema puede entenderse, como tantos otros elementos de la cultura náhuatl, desde una perspectiva religiosa o desde una perspectiva reflexiva. Según la religión, el destino de los seres humanos está completamente trazado de antemano:

desde que el hombre nace [...] se encuentra automáticamente inserto en este orden [...] El signo del día de su nacimiento lo dominará hasta su muerte: aun llegará a determinarla y, por consecuencia, también determinará su vida en el más allá [...] Su suerte entera está sometida a una rigurosa predeterminación. ${ }^{18}$

Este sometimiento era tal que ni siquiera los mismos dioses se encontraban por encima de él, una concepción que podría acercarse a la griega de las Moiras o a la germánica de las Nornas. Por ello, aunque "sin duda se hacían intentos para enmendar el destino [...] no parece que hayan existido grandes esperanzas de sustraerse a la mecánica inexorable" ${ }^{, 19}$ del mismo.

Sin embargo, León-Portilla alerta de que esa idea del fatalismo náhuatl, por extendida que se halle, debe analizarse con cuidado. La idea clave para emprender este

\footnotetext{
${ }^{16}$ León-Portilla, La filosofía náhuatl, 229.

17 Véase Robert Kane (ed.), The Oxford Handbook of Free Will (Nueva York: Oxford University Press, 2002).

18 Jacques Soustelle, La vida cotidiana de los aztecas en vísperas de la conquista (México: Fondo de Cultura Económica, 1992), 120.

${ }^{19}$ Ibid., 120-121.
} 


\section{enn-claves}

análisis es que, si bien los nahuas creían que los signos y las fechas del tonalpohualli [calendario] ejercen un influjo sobre los seres humanos y las sociedades, no resulta menos cierto que, "a excepción de algunos pocos casos [...] por el control de sí mismo [...] se puede superar un destino fatal, así como por negligencia es posible arruinarse $" .{ }^{20}$ Bolea, por su parte, afirma que "el signo del día marcaba lo que ahora se llamaría temperamento o personalidad y era algo que no se podía cambiar". ${ }^{21}$ Este uso de la terminología moderna permite transponer las declaraciones de León-Portilla al marco de referencia actual: aunque el temperamento de un sujeto sea algo que permanece más o menos constante a lo largo de su vida, es cierto también que no representa un destino del que no se puede escapar. Entonces, se habrá de reconocer, como adecuadamente hace León-Portilla, que las concepciones de los aztecas a este respecto difícilmente pueden identificarse con el fatalismo. Al mismo tiempo, la referencia al autocontrol conduce a hablar de un tema tan destacado para la ética como es la educación, el factor capaz de hacer que los sujetos se sustraigan a su destino, además, de reproducir la estructura social considerada deseable.

\section{Educación e ideales de persona}

Fernando Díaz-Infante aporta una intuición sobre los mexicas que, pese a ser altamente polémica, puede servir para introducir el tema de la educación en el mundo náhuatl. Según este autor, los mexicas eran un "pueblo adolescente". 22 tanto sus cualidades como sus defectos eran los propios de una personalidad que aún se encontraba inmersa en el proceso de maduración. Este hecho explicaría que, en lo que podría denominarse su inconsciente colectivo (sin entrar a discutir las complejidades de esta caracterización) todavía se tuviesen que superar temores propios de la infancia, como el miedo a la pobreza o al rechazo y marginación de que fueron objeto cuando se asentaron en el valle de México. Según DíazInfante, lo que les ayuda a superar estos miedos es precisamente su mística religiosa, centrada en el culto a Huitzilopochtli, un dios guerrero. ${ }^{23}$

\footnotetext{
${ }^{20}$ León-Portilla, La filosofía náhuatl, 198.

21 Marcela Bolea Murga, "Reseña histórica de la educación a la primera infancia en México", Ethos Educativo, núm. 42 (2008): 27.

${ }^{22}$ Fernando Díaz-Infante, La educación de los aztecas. Como se formó el carácter del pueblo mexica (México: Panorama, 1982), 32.

${ }^{23}$ Véase Alfonso Caso, El pueblo del Sol (México: Fondo de Cultura Económica, 2009), 23-24.
} 


\section{enn-claves}

Pero tal mística no explica por sí sola la mentalidad del pueblo azteca, pues en ésta “convergen las dos formas de vida que practicaron los pueblos de Mesoamérica: la guerrera y la humanista". ${ }^{24}$ La primera, procedente de los mismos orígenes del pueblo azteca en las tierras del norte, se identifica, como acaba de verse, con el culto a Huitzilopochtli. La segunda, a su vez, fue adquirida a través del contacto con las culturas de la meseta central, en especial con los toltecas, y se identifica con el culto a Quetzalcóatl. Esto sugiere la existencia de dos corrientes subyacentes en el pensamiento mexica, la guerrera y la humanista (a la que se le sumaría también una tercera influencia, el culto a Tláloc, dios de la lluvia, una deidad adorada desde muy antiguo en toda Mesoamérica). Tales formas de vida, aparentemente contradictorias, se equilibraban en la mentalidad mexica.

¿Qué influencia ejercieron sobre la educación y la moralidad azteca las dos corrientes citadas? Como hipótesis de trabajo, admitiendo que se trata hasta cierto punto de un experimento mental, podría establecerse una relación entre el culto a ambos dioses y la existencia de diversos ideales de persona en el mundo azteca, expresados o caracterizados a través de conjuntos de virtudes. Así pues, se hará referencia a la educación y enseguida a las virtudes utilizando como punto de contacto entre ambos elementos, precisamente, a los ideales de persona. Para quitar algo de ambigüedad a esta expresión, se pondrán un par de ejemplos.

El primero es el ideal del guerrero, común a numerosas culturas, muy distantes en el tiempo y el espacio. En el caso de la cultura náhuatl, el ideal tiene que ver directamente con el culto a Huitzilopochtli y con la concepción antropocéntrica del cosmos citada anteriormente, los cuales convierten a la valentía en una actitud que considera a la muerte como algo deseable. Por poner un único ejemplo, ya que habría muchos otros presentaremos el siguiente fragmento de Sahagún:

hacedlos esforzados y osados, y quitad toda cobardía de su corazón, para que con alegría [y] no solamente con alegría, reciban la muerte, pero que la deseen y la tengan por suave y dulce, y que no teman las espadas ni las saetas, más que

\footnotetext{
${ }^{24}$ Díaz-Infante, La educación de, 36.
} 


\section{en-claves}

las tengan por cosa dulce y suave como a flores y manjares suaves, ni teman ni se espanten de la grita y alaridos de sus enemigos. ${ }^{25}$

El segundo es el ideal del sabio, relacionado directamente con el culto a Quetzalcóatl, la toltecáyot ${ }^{26}$ y la educación, tal y como muestra este fragmento del Códice Matritense de la Real Academia:

El mismo es escritura y sabiduría.

Es camino, guía veraz para otros.

Conduce a las personas y a las cosas, es guía en los negocios humanos.

El sabio verdadero es cuidadoso (como un médico) y guarda la tradición.

Suya es la sabiduría trasmitida, él es quién la enseña, sigue la verdad.

Maestro de la verdad, no deja de amonestar.

Hace sabios los rostros ajenos, hace a los otros tomar una cara (una personalidad), los hace desarrollarla.

Les abre los oídos, los ilumina.

Es maestro de guías, les da su camino, de él uno depende.

Pone un espejo delante de los otros, los hace cuerdos, cuidadosos; hace que en ellos aparezca una cara (una personalidad).

Se fija en las cosas, regula su camino, dispone y ordena.

Aplica su luz sobre el mundo.

Conoce lo [que está] sobre nosotros [y], la región de los muertos.

[Es hombre serio].

Cualquiera es confortado por él, es corregido, es enseñado.

Gracias a él la gente humaniza su querer y recibe una estricta enseñanza.

Conforta el corazón, conforta a la gente, ayuda, remedia, a todos cura. ${ }^{27}$

Ideales de lo que es una persona, como los citados, ${ }^{28}$ ejercían una amplia influencia en las que, según Ortiz, eran las tres principales instancias a través de las cuales se llevaba a cabo la tlacahuapahualitztli — que suele traducirse como 'el arte de crear o educar a los hombres'- en el mundo náhuatl: (1) la familia, (2) la educación formal y (3) el

\footnotetext{
${ }^{25}$ Fray Bernardino de Sahagún, Historia general de las cosas de Nueva España. Tomo II (México: Editorial Pedro Robredo, 1938), 54.

${ }^{26}$ Esta palabra, traducida como 'toltequidad', era empleada por los mexicas para referirse al legado de los toltecas y abarcaba lo más elevado de su cultura: el calendario, la escritura, la sabiduría, la astronomía, las artes, etc. Miguel León-Portilla, Toltecáyotl (México: Fondo de Cultura Económica, 2003), 7.

${ }^{27}$ León-Portilla, La filosofía náhuatl, 65.

${ }^{28}$ Otro ideal especialmente destacado sería el pochteca o comerciante, que comparte muchos rasgos comunes de la moralidad náhuatl pero también añade algunos otros propios y originales.
} 


\section{enn-claves}

Gobierno. ${ }^{29}$ Posteriormente, se mostrarán ejemplos de varias de las virtudes que eran fomentadas desde tales instancias. Sin embargo, antes de pasar a exponer ese catálogo de virtudes, se quisiera comentar algunas cuestiones teóricas sobre éstas.

\section{Educando en las virtudes}

El concepto de virtud ${ }^{30}$ posee una larga historia, en la cual se puede destacar su primera gran teorización a cargo de Aristóteles, quien en su Ética nicomáquea liga el concepto con la conocida doctrina del justo medio, así como santo Tomás, quien da un giro teológico al concepto aristotélico, al considerar que la finalidad del ser humano no es ejercer la racionalidad en este mundo, sino llegar a unirse con Dios en el otro. Por ello, añade a las cuatro virtudes cardinales de Aristóteles las tres virtudes teologales (fe, esperanza y caridad) y otras, como la humildad, específicas del cristianismo. En la actualidad, el principal teórico de las virtudes es Alasdair MacIntyre, quien interpreta a las mismas como "cualidades necesarias para lograr los bienes internos a una práctica", y también "como cualidades que contribuyen al bien de una vida completa", teniendo en cuenta además que las virtudes siempre tienen "relación con la búsqueda del bien humano, cuyo concepto sólo puede elaborarse y poseerse dentro de una tradición social". ${ }^{31}$

Después de este brevísimo repaso de antecedentes, se tratará de relacionar el concepto de virtud con el mundo moral de los aztecas, y en particular con sus procesos educativos. Un primer punto de contacto lo ofrece el hecho de que, desde el inicio del libro VI de su Historia general, Sahagún enfrenta el tema de la filosofía moral náhuatl desde una perspectiva fácilmente asimilable a la de las virtudes. No sólo utiliza los términos 'virtud' o 'virtudes' en varios lugares de su exposición, sino que, a lo largo de la misma, se refiere en

\footnotetext{
${ }^{29}$ Carlos E. Ortiz, "Educación ética de los jóvenes en la familia náhuatl. Análisis del Huehuetlatolli", Anuario de Historia de la Iglesia 15 (2006): 391-394.

${ }^{30}$ En general, se suele considerar a las virtudes (por ejemlo, la honestidad o la templanza) como disposiciones o rasgos del carácter persistentes que informan de una manera coherente la conducta de los seres humanos. Las virtudes configuran la personalidad de los agentes, al hallarse relacionadas con otros muchos elementos como las actitudes, las decisiones o las percepciones. De hecho, según MacIntyre, las virtudes no sólo disponen a actuar de un modo particular, sino también a sentir las cosas de un modo particular. De este modo, cuando alguien actúa de forma virtuosa, no se trata de que esté actuando contra sus propias inclinaciones (como pretenden otras escuelas filosóficas) sino, más bien, de que actúa de acuerdo con inclinaciones que han sido conformadas por el cultivo constante de las virtudes.

${ }^{31}$ Alasdair MacIntyre, Tras la virtud (Barcelona: Crítica, 1987), 333.
} 


\section{enn-claves}

numerosas ocasiones a diferentes modos de actuar, los cuales rinden o no sus frutos, es decir, a lo que podría caracterizarse como virtudes. En relación con el pensamiento mexica, debe decirse que sin duda existieron 'virtudes' comunes o fácilmente asimilables a algunas de la tradición occidental, como la propia humildad o la obediencia, las cuales es de creer que habrían sido de gran utilidad en el proceso de aculturación.

Para seguir relacionando el tema de las virtudes con la educación, Mina Markus señala que la tlacahuapahualitztli era un proceso que comenzaba en la infancia. En el seno de la casa familiar, a las niñas y niños se les inculcaban valores, como el respeto a los dioses, a los pobres e inválidos y a los mayores (el respeto a éstos era tal que incluso en la edad adulta apenas se atrevían a hablar delante de sus padres). ${ }^{32}$ La obediencia a los padres, o al marido en el caso de las niñas, era también un valor muy destacado, así como la discreción, el agradecimiento para con los demás y el no romper las promesas. Se trataba de un proceso educativo de tipo "tradicionalista, ya que pretendía trasmitir los usos y costumbres de las generaciones pasadas". ${ }^{33}$ Asimismo, la educación proporcionada en el hogar "era muy estricta",34 y variaba de acuerdo a la edad de los educandos, desde el régimen alimenticio hasta los castigos que se imponían, los cuales eran más duros a medida que los niños iban creciendo.

La castidad era una de las virtudes más destacadas por los mexicas. Debido a ello, era promovida en el seno del hogar cuando hijas e hijos ${ }^{35}$ llegaban a una determinada edad. El siguiente fragmento, por ejemplo, está destinado a los hombres, aconsejándoles guardar un comportamiento casto antes del matrimonio.

No te arrojes a la mujer como el perro se arroja a lo que ha de comer, no te hagas a manera de perro en comer y tragar lo que le dan, dándote a las mujeres antes de tiempo; aunque tengas apetito de mujer resístete, resiste a tu corazón hasta que ya seas hombre perfecto y recio [...] y entonces estarás hábil para el casamiento y engendrarás hijos de buena estatura y recios, y ligeros y hermosos y de buenos rostros. ${ }^{36}$

\footnotetext{
32 Mina Markus S., "Estudio comparativo entre la educación náhuatl y la griega", Estudios de Cultura Náhuatl, núm. 4 (1963): 281-292.

${ }^{33}$ Bolea, "Reseña histórica", 25.

${ }^{34}$ Markus, "Estudio comparativo", 288.

${ }^{35}$ No se restringía a las mujeres, aunque su virginidad se valoraba de manera especial.

${ }^{36}$ Sahagún, Historia general, 143.
} 


\section{enn-claves}

Al cumplir los quince años, ${ }^{37}$ los niños debían entrar a un centro educativo, ${ }^{38}$ generalmente, el Telpochcalli o el Calmecac, adentrándose en el proceso que algunos autores caracterizan como "educación formal". 39 El primer centro - la "Casa de los Jóvenes"- se destinaba a la formación de los guerreros, mientras que el segundo estaba destinado principalmente a los hijos de la nobleza. Debido a que existen numerosos estudios acerca de la educación en estos centros, ha parecido más interesante poner un ejemplo de cómo actuaba, y qué virtudes promovía, la tercera instancia educativa del mundo azteca: el Gobierno.

El capítulo XIV del mismo libro VI de Sahagún ofrece una larga exhortación ofrecida al pueblo por su gobernante, en el momento de la elección de éste. Los imperativos que aparecen en esta plática son interesantes y pueden entenderse como normas morales que regulaban el mundo azteca. Y, al respecto, resulta interesante darse cuenta de que la primera recomendación es apartarse del alcohol: el uctli es caracterizado como la "raíz y principio de todo mal y de toda perdición [...] que trae consigo todos los males juntos"40 desde los adulterios y la corrupción de menores hasta la soberbia y los robos. Una de las principales razones por las cuales el alcohol resulta tan negativo es que "los borrachos [...] están fuera de sí". ${ }^{41}$ Para una cultura que valoraba tanto el autocontrol, salirse de uno mismo durante la embriaguez necesariamente debió de haberse visto como una de las peores amenazas para la integridad moral. Así, antes de pasar a otros temas, el gobernante recién elegido narra los castigos que se reservan a los alcohólicos, algunos causados por su propia negligencia, otros por intervención divina, y también los variados castigos infligidos por la justicia humana.

Como se ha visto, una de las principales preocupaciones educativas era el formar en las virtudes necesarias para ejercer diversas actividades en la vida. Con el fin de mostrar un

${ }^{37}$ Otros autores dicen ocho años: véase Amparo R. de Parres, "La niñez en el Códice Mendocino", Perinatología y reproducción humana 15, núm. 1 (2001): 91.

${ }^{38}$ León-Portilla señala en Toltecáyotl que en los tiempos prehispánicos todos los niños tenían abierta la posibilidad de recibir educación, lo cual generalmente era una obligación para los padres, y contrasta esta situación con el México actual.

39 Reginaldo Aliçandro Bordin, "A educaçao asteca nos seus aspectos formal e informal", Revista CESUMAR-Ciências Sociais e Humanas Aplicadas 7, núm. 1 (2002): 55-75.

${ }^{40}$ Sahagún, Historia general, 99.

${ }^{41}$ Ibidem. 


\section{enn-claves}

buen ejemplo de esta clase de virtudes aplicadas, se ha seleccionado el capítulo X del libro VI de Sahagún, el cual expone la admonición que algún personaje principal, especialmente, un alto sacerdote, hacía al gobernante recién elegido. El texto es interesante porque, en medio de la retórica propia de estas ocasiones, centrada en asuntos como la pesada carga que representa el gobierno, el discurso muestra también un retrato del gobernante ideal, señalando tanto las virtudes que deben adornarlo como los vicios que debe evitar. Según este discurso, el gobernante debe ser trabajador, humilde, justo, calmado, benevolente, grave, severo y digno. Debe ser consciente en todo momento de que representa a Tloque Nahuaque en el mundo. Debe saber escuchar; no debe ser holgazán, dormilón, irascible ni gastador. Otro aspecto que protagoniza muchas exhortaciones es la devoción. Según la imagen que surge de las fuentes consultadas, todos los señores mexicas eran personas devotas, hasta un grado que podría caracterizarse, usando (o abusando de) la terminología del cristianismo, como santidad.

El capítulo VI del libro VI de Sahagún también muestra una oración que se rezaba cuando se quería pedir a Tezcatlipoca que le retirase el dominio sobre el pueblo (matándolo o de cualquier otra manera) al señor que no llevase a cabo su trabajo adecuadamente. Por ello, constituye un interesante contrapunto a lo expuesto hasta ahora, al permitir observarlo desde la perspectiva opuesta, es decir, la de los vicios que incapacitan al gobernante.

tiene un corazón cruel y duro, y usa de la dignidad que le habéis dado así como el borracho usa del vino [...] La prosperidad le hace que a todos menosprecie [...] Parece que su corazón está armado de espinas muy agudas, y también su cara $[\ldots]$ No cura de nadie, ni toma consejo con nadie [...] No es devoto ni ora a los dioses, ni llora delante de ellos, ni se entristece por sus pecados. ${ }^{42}$

\section{Un principio ético: in quálli, in yéctli}

Después de haber observado algunas de las virtudes (y vicios) que aparecen en un lugar tan destacado de la cultura náhuatl, se quisiera presentar uno de sus principios normativos más elevados, que ayudará a completar este recorrido panorámico por la moralidad de la misma. Para ello, se comenzará leyendo un poema recogido por Fray Andrés de Olmos.

\footnotetext{
${ }^{42}$ Sahagún, Historia general, 63-64.
} 


\section{en-claves}

Es conveniente, es recto:

ten cuidado de las cosas de la tierra:

[...] tendrás qué beber, qué comer, qué vestir.

Con eso estarás en pie (serás verdadero)

con eso andarás.

Con eso se hablará de ti, se te alabará,

Con eso te darás a conocer a tus padres y parientes. ${ }^{43}$

La primera línea de este poema alude a lo que León-Portilla denomina "el principio supremo que dentro de la sociedad normaba las relaciones jurídicas de sus miembros". ${ }^{4}$ Para justificar la introducción de esta clase de consideraciones de orden jurídico en el ámbito de la moral, debe hacerse una breve referencia a la separación entre ética y derecho, cuestión que se puede abordar desde muy diferentes perspectivas. Una visión muy común en la ética contemporánea consiste en establecer diferencias nítidas, à la Kant, entre ambos campos. Sin embargo, existen alternativas, como la expuesta por el pragmatismo legal, bien en los textos clásicos, ${ }^{45}$ bien en los de herederos contemporáneos de esta corriente. ${ }^{46}$ Haciendo un resumen muy breve de esta posición (y confesando su cercanía al naturalismo normativo de John Dewey), se dirá que, según el pragmatismo, las normas jurídicas sobrevienen a los hábitos, de modo que las reglas del derecho son descendientes de las costumbres, lo cual haría muy difícil separar nítidamente derecho y moral. Debido a ello, no se considera incorrecto incluir un principio jurídico en una exposición de la moral azteca, sobre todo teniendo en cuenta que se trata de un principio de tan elevada categoría.

Ahora bien, ¿cuál es este principio supremo? Se trata del conocido in qualli, in yectli, que suele traducirse como 'lo conveniente, lo recto'. Este principio no sólo regulaba "las obligaciones de cada persona respecto de sí misma [sino también las que se daban] en

\footnotetext{
${ }^{43}$ León-Portilla, La filosofía náhuatl, 236-237.

${ }^{44}$ León-Portilla, Toltecáyotl, 318.

${ }^{45}$ Véase Oliver Wendell Holmes, The Path of the Law (Bedford, MA: Applewood, 2006); y The Common Law (Toronto: University of Toronto School of Law, 2011); Benjamin N. Cardozo, The Nature of the Judicial Process (Nueva Orleans: Quid Pro Law Books, 2010); John Dewey, "Logical Method and Law", The Philosophical Review 33, núm. 6 (1924): 560-572, y "My Philosophy of Law”, en John Dewey, The Later Works, 1925-1953. Vol. 14. 1939-1941. Essays, Reviews and Miscellany (Carbondale: Southern Illinois University, 1988).

${ }^{46}$ Véase Richard A. Posner, "Legal Pragmatism Defended”, The University of Chicago Law Review 71, núm. 2 (2004): 683-690.
} 


\section{enn-claves}

relación con sus semejantes y con el estado". ${ }^{47}$ Se trata, pues de un principio que a la vez regula las dimensiones privada y pública de la moralidad. Tal y como explica León-Portilla, en una determinada situación el principio obligaba a buscar, primero, lo conveniente para la persona que actuaba. Al mismo tiempo, obligaba a ésta a buscar lo recto y conveniente en sí mismo, garantizando que el curso de acción que se siguiera no dañase los intereses de otros miembros de la sociedad y, por ende, que no perjudicara a ésta. Para León-Portilla, este principio "equivale al concepto occidental de justicia". ${ }^{4}$

Pueden verse ejemplos de la utilización práctica de este principio en diversas dimensiones de la vida social de los mexicas, como la guerra o el comercio. La tenencia de la tierra, un aspecto clave para entender la economía prehispánica, también dependía de este principio. Cuando los mexicas se establecieron en el Valle de México, la primera distribución de tierras que se hizo entre los diversos calpulli fue de tipo comunal, y se basó en el principio citado. Cada grupo necesitaba una porción de tierra para alimentarse; esta necesidad indiscutible trajo aparejado un concepto de decisiva importancia para la ideología mexica: quienes poseen la tierra, deben trabajarla. La tierra es propiedad de alguien "si se encuentra vinculad[a] con su rostro, si es su pertenencia por habérselo acercado", y tal concepto de vinculación-acercamiento supone "una relación dinámica y constante [entre la tierra y los seres humanos] por medio del trabajo". 49

Esta relación sufrió numerosos cambios, algunos durante la propia época prehispánica, en la cual comenzó a aparecer la propiedad privada (al principio de los nobles — pipiltin - y más tarde de los comerciantes). Otros cambios llegaron más tarde. No se hablará aquí de la Colonia, ni de la Independencia, únicamente de la Revolución: el famoso lema atribuido a Emiliano Zapata, la tierra es de quien la trabaja, podría entenderse como una actualización del viejo principio, que seguiría resonando en las mentes de muchos mexicanos.

\footnotetext{
${ }^{47}$ León Portilla, Toltecáyotl, 318-319.

${ }^{48}$ Ibid., 319.

${ }^{49}$ Ibid., 320.
} 


\section{en-claves}

\section{Reflexiones finales}

Para terminar, se quisiera primero señalar el elevado nivel moral de la sociedad mexica, tal

y como reconoce el propio Sahagún. Tan alto nivel suscita, desde luego, interesantes comparaciones, entre las cuales se desea destacar una en particular, referente al concepto democrático de las virtudes en el mundo náhuatl, que se puede contraponer fácilmente con el concepto aristocrático de los griegos. En el tema de la educación también se encuentran elementos susceptibles de establecer una comparación con Grecia, donde la educación y sus beneficios estaban limitados a una clase social, mientras que en la sociedad azteca se trataba prácticamente de lo que hoy podría denominarse un derecho universal.

También se quisiera decir que iniciativas como que hemos venido desarrollando en este texto parecen una forma interesante de renovar la filosofía latinoamericana, prestando atención a modelos no-europeos, sea históricos, como es el caso de este artículo, sea de los pueblos originarios que hoy por hoy habitan Latinoamérica (una alternativa que debería explorarse mucho más). Este texto se ha limitado a trazar el panorama de una moralidad histórica, pero sería fácil avanzar en la especulación, preguntando por ejemplo cómo se podría actualizar el pensamiento de los mexicas para intentar responder a algunas interrogantes de hoy. ¿Podría renovarse el pensamiento náhuatl de forma que arroje intuiciones, por ejemplo, sobre cuestiones que ocupan hoy a la filosofía moral, como el cambio climático, la clonación o los transgénicos? En este punto, se apuesta por el optimismo. No será una tarea fácil, pero se cree que es posible hacerlo. La riqueza teórica que puede desprenderse de un diálogo con el pensamiento náhuatl, en el caso de la ética y de otras muchas ramas de la filosofía, obliga a intentarlo. 


\section{en-claves}

Revista de Filosofía, Arte, Literatura, Historia

e-ISSN: 2594-1100, Año XIV, Núm 27, enero-junio 2020, 19-38

\section{Bibliografía}

Appiah, Kwame Anthony. Experiments in Ethics. Cambridge, MA: Harvard University Press, 2008.

Bolea Murga, Marcela. "Reseña histórica de la educación a la primera infancia en México". Ethos Educativo, núm. 42 (2008): 25-60.

Bordin, Reginaldo Aliçandro. "A educaçao asteca nos seus aspectos formal e informal”. Revista CESUMAR-Ciências Sociais e Humanas Aplicadas 7, núm. 1 (2002): 55-75.

Callicott, J. Baird. Earth's Insights. A Survey of Ecological Ethics from the Mediterranean Basin to the Australian Outback. Berkeley: University of California Press, 1994.

Cardozo, Benjamin N., The Nature of the Judicial Process. Nueva Orleans: Quid Pro Law Books, 2010.

Caso, Alfonso. El pueblo del sol. México: Fondo de Cultura Económica, 2009.

Cortina, Adela, y Emilio Martínez Navarro. Ética. Madrid: Akal, 2008.

Dewey, John. "Logical Method and Law". The Philosophical Review 33, núm. 6 (1924): 560-572.

Dewey, John. "My Philosophy of Law”. En John Dewey, The Later Works, 1925-1953. Volume 14. 1939-1941. Essays, Reviews and Miscellany. Carbondale: Southern Illinois University, 1988.

Díaz-Infante, Fernando. La educación de los aztecas. Como se formó el carácter del pueblo mexica. México: Panorama, 1982.

Garibay, Ángel María. Llave del náhuatl. Colecciones de trozos clásicos, con gramática y vocabulario náhuatl-castellano, para utilidad de los principiantes. México: Porrúa, 2007.

Garza, Mercedes de la. El hombre en el pensamiento religioso náhuatl y maya. México: Universidad Nacional Autónoma de México, 1978.

González, Ana Marta. "Ética y moral. Origen de una diferencia conceptual y su trascendencia en el debate ético contemporáneo”. Anuario Filosófico, núm. 33 (2000): 797-832.

Holmes, Oliver Wendell Jr. The Path of the Law. Bedford, MA: Applewood, 2006. 


\section{en-claves}

Holmes, Oliver Wendell Jr. The Common Law. Toronto: University of Toronto School of Law, 2011.

Jaeger, Werner W. Paideia. Los ideales de la cultura griega. México: Fondo de Cultura Económica, 1944.

Kane, Robert (ed.). The Oxford Handbook of Free Will. Nueva York: Oxford University Press, 2002.

León-Portilla, Miguel. La filosofía náhuatl estudiada en sus fuentes. México: Universidad Nacional Autónoma de México, 1974.

León-Portilla, Miguel. Bernardino de Sahagún. Pionero de la antropología. México: Instituto de Investigaciones Históricas de la Universidad Nacional Autónoma de México, 1999.

León-Portilla, Miguel. Toltecáyotl. Aspectos de la cultura náhuatl. México: Fondo de Cultura Económica, 2003.

MacIntyre, Alasdair. Tras la virtud. Barcelona: Crítica, 1987.

Markus S., Mina. "Estudio comparativo entre la educación náhuatl y la griega” Estudios de Cultura Náhuatl, núm. 4 (1963): 281-292.

Ortiz, Carlos E. Educación ética de los jóvenes en la familia náhuatl. Análisis del Huehuetlatolli [Tesis doctoral] Pontificia Universitas Lateranensis, Roma, Italia, 2005.

Ortiz, Carlos E. "Educación ética de los jóvenes en la familia náhuatl. Análisis del Huehuetlatolli”. Anuario de Historia de la Iglesia 15 (2006): 391-394.

Parres, Amparo R. de. "La niñez en el Códice Mendocino". Perinatología y reproducción humana 15, núm. 1 (2001): 89-95.

Posner, Richard A. "Legal Pragmatism Defended". The University of Chicago Law Review 71, núm. 2 (2004): 683-690.

Rorty, Richard. "La historiografía de la filosofía: cuatro géneros". En Richard Rorty, Jerome B. Schneewind y Quentin Skinner (eds.), La filosofia en la historia. Ensayos de historiografía de la filosofía. Barcelona: Paidós, 1990.

Sahagún, Fray Bernardino de. Historia general de las cosas de Nueva España. Tomo II. México: Editorial Pedro Robredo, 1938. 


\section{enn-claves}

Soustelle, Jacques. La vida cotidiana de los aztecas en vísperas de la conquista. México: Fondo de Cultura Económica, 1992.

Vicente Castro, Florencio, y José Luis Rodríguez Molinero. Bernardino de Sahagún. El primer antropólogo en Nueva España (Siglo XVI). Salamanca: Universidad de Salamanca, 1986.

\section{Agradecimientos}

Este artículo es producto de una estancia breve de investigación en el Instituto de Investigaciones Históricas de la Universidad Nacional Autónoma de México, realizada en febrero del 2011. Agradezco el haberme aceptado para dicha estancia, lo cual siempre será para mí un enorme motivo de orgullo, a Miguel León-Portilla (lamentablemente fallecido durante el proceso de dictamen de este artículo, pero vivo en el corazón de mucha gente) y a Iván Escamilla González su apoyo durante el desarrollo de la estancia. A Lu, Viviana y Uriel les agradezco por haberme facilitado el alojamiento. A Heidy Miguel Ramírez su apoyo como servicio social. 